Session 2509

\title{
Electrocardiogram Capture and Analysis
}

\author{
Paul H. King, Ph.D., P.E. \\ Vanderbilt University
}

\begin{abstract}
This paper describes an introductory freshman seminar titled Electrocardiogram Capture and Analysis, taught at Vanderbilt University in Fall 2000. The class was one of several optional introductory one credit hour modules offered to entering freshmen students. The intent of the modules was to allow entering students to select an informal introduction to a field of interest to them, one that presumably could give them an early motivation for their selected field of study. This course was designed to parallel an introductory engineering course required of all entering students, and was intended to allow students to learn how to apply their skills acquired in the required course to the analysis of electrocardiograms. The course was well-received and got good student reviews. The course structure and evaluation will be reviewed below.

Introduction

The Vanderbilt University School of Engineering has had a rather "plain vanilla" common freshman year sequence for a number of years. Entering freshmen take General Chemistry, Analytic Geometry and Calculus, a humanities elective, and an Introduction to Computing in Engineering Course. The spring semester brings a continuation of the math and chemistry, with the addition of Physics and an introductory computer science course.

The freshman year typically brings an attrition of students, one of the more common complaints heard by this author is that "engineering is too hard", when in fact the students have not really had any introduction (in most cases) to material relating to their interests. In an attempt to allow the students an option to take material as first semester freshmen in a non threatening environment and to introduce them to (generally) senior level faculty in their department of interest, the school requested that faculty volunteer to teach one credit hour modules (aka freshman seminars) to interested small groups. The instructor set class maximum size.

Twelve modules will be taught this school year. Fall semester modules that were offered consisted of such titles as "Frontiers in Mechanical Engineering", "Readings in Contemporary Technology", "High Fidelity Sounds", and "Moore's Law." Spring offerings will include modules titled "Entrepreneurship", "Clinical Research", and "Topics in Biochemical Engineering". The course "Electrocardiogram Capture and Analysis" was taught in the fall term, the remainder of this paper will cover the structure of this course and the student responses from the initial offering.
\end{abstract}

Course Structure

Proceedings of the 2001 American Society for Engineering Education Annual Conference \& Exposition Copyright @ 2001, American Society for Engineering Education 
In planning this course, there were just a few considerations in the lecture sequence. The course plans called for both Excel and MATLAB analyses of electrocardiograms, this work was to be relegated to classes after the basics of Excel and MATLAB were covered in the required Introduction to Computing course mentioned above. Other portions of the class sequence then depended on the authors' ability to get guest speakers to cover specific areas of interest to the course, the remainder of the course material was then filled by the instructor who has devoted a portion of his career to EKG analysis (Skylab flights, more recently EKG studies on mice in a Pharmacology department) and related matters. The course was scheduled for a two-hour block in the afternoon; students were informed that class each week would consist of a one-hour lecture or a two-hour laboratory visit. The topics covered in the course are listed below:

- Basic medical nomenclature (construction of medical words, especially those relating to cardiology)

- Overview of the evolution of the heart and structure/function

- The heart as a pump, normal electrocardiogram generation, excitable tissue

- EKG capture (in-class capture of student electrocardiograms, discussion while doing so)

- General lecture on and demonstration of bioelectric signals

- Lecture by a cardiologist on heart problems and electrocardiogram interpretation

- Lecture on analog to digital conversion

- Visit to a Human Patient Simulator, lecture on intubations and monitoring, hands-on intubation

- Visit to a mouse research laboratory, witnessing of electrocardiogram transmission and data capture system

- Lecture and demonstration of pacemakers and defibrillators by a Medtronic Field engineer

- Lecture/demonstration of EKG analysis using Excel

- Lecture and demonstration of EKG analysis using MATLAB

- Course summary and evaluation.

Specifics regarding course details such as homework examples and references may be found at: http://vubme.vuse.vanderbilt.edu/King/ekg2000.htm

Evaluation

Evaluation of students was through homework exercises, no final exam appeared to be necessary. Eighteen students began the course, seventeen finished; attendance was generally much better than that experienced with seniors. The one student that dropped the course did so only because of time constraints due to military service. All students that completed the course 
were planning to major in Biomedical Engineering at the start of the term. The students remained motivated all semester.

Evaluation of the course and instructor was done with written comment forms and with computer score sheets. The written forms included positive comments such as: "I liked getting a hands-on experience," "... better understanding of what I will be doing ...", "enjoyed the variety...," "I want to go father ...", etc. A shocker was: "Being an EMT, I was familiar with most of the subject material, but it was interesting to learn about the things more in depth. I now have a better understanding of the tools that I have used." A few students asked for more field trips, two thought the course was too easy; three thought it was too hard, one thought he "learned for the sake of learning", which was a goal of the class. Overall, this coverage of subject was very well received.

This work was supported in part by the Engineering Research Centers Program of the National Science Foundation under Award Number EEC-9876363. This course will be offered again in 2001.

PAUL H. KING

Paul H. King is an Associate Professor of Biomedical Engineering at Vanderbilt University. He holds similar titles in Mechanical Engineering and in Anesthesiology at Vanderbilt. He has taught Biomedical Engineering at Vanderbilt for the past 35 years, his current area of concentration is Senior Design in both his research and teaching roles. 